\title{
Phylogenetic Differentiation of Cultivated Rice, XX Analysis of the Genetic Basis of Hybrid Breakdown in Rice ${ }^{1)}$
}

\author{
Hiko-Ichi OKa and Yukio DoIda \\ National Institute of Genetics, Misima
}

Received June 27, 1961

Distantly related varieties of cultivated rice (Oryza sativa L.) often show partial sterility in their $F_{1}$ hybrids. The senior writer formerly demonstrated that this sterility could be accounted for by gametic-development genes, i.e., duplicate genes whose double recessive combinations interrupt the development of gametes carrying them (Oka 1953, 1957b). This hypothesis could plausibly explain segregation in certain ratios of fertile and partially sterile plants in experimental crosses, modification of $F_{2}$ ratios for various characters and other phenomena characteristic of the hybrid sterility in cultivated rice. However, on its basis, sterility should occur only in heterozygotes for the gametic development genes. Thus, a fertile plant should produce only fertile plants in the progeny, while a semi-sterile plants should produce fertile plants and semi-sterile ones whose fertility is not lower than that of the parent, and a true-breeding semisterile line could not be established. Actually, partially sterile plants have often been found in the $F_{2}$ and later generations derived from a highly fertile $F_{1}$ hybrid, and lines true-breeding for sterility appeared in the progeny of such partially sterile plants.

The present study showed that besides the gametic-development genes, there is another genic system responsible for the sterility in hybrid derivatives.

\section{Materials and Methods}

As mentioned in a previous paper of this series (Oka 1954), many rice strains from various Asian countries were crossed with a certain set of test-strains in order to survey the pattern of hybrid sterility relationships. Using a part of those crosses, fertility variations in $\mathrm{F}_{2}$ and later generations were observed. The parental strains, which were established after repeated self-pollination from a single plant, could be regarded as virtually pure, and were completely self-fertile. The partially sterile lines used for the present work were obtained from the above-mentioned crosses. Detailed accounts for particular strains and methods of analysis of the data will be given together with the results.

The plants were grown in the experimental field of the National Institute of

1) Contribution from National Institute of Genetics, Japan, No. 379. The writers are grateful for the generous financial support of this work by The Rockefeller Foundation (RF57080; Studies on the origin of cultivated rice), and by the Ministry of Education, Government of Japan (a grant-in-aid for scientific research). 
Genetics, Misima, Japan or in Taiwan Prov. Agricultural College, Taichung (as indicated in respective tables), in proper rice growing seasons with a moderate amount of fertilizers. Care was taken to avoid disturbances due to strong winds, too low or too high temperatures, etc., and plants supposedly affected by such unfavorable conditions were discarded. Both the percentages of seed setting (measured with five or more panicles per plant) and good pollen (stained with iodine solution) were recorded on a single plant basis, but the data for seed fertility were mainly used for analytical studies for the reason that will be mentioned later.

\section{Results}

\section{Fertility variations in $F_{2}$ and later generations}

In many intervarietal crosses, the mean seed-fertility of $F_{2}$ plants was compared with the $F_{1}$ fertility. The results are given in Fig. 1, in which crosses between the India (Continental) and the Japonica (Insular) types are shown by solid dots, and those between varieties of the same type by circles. The scatter diagram shows that the $F_{1}$ and $F_{2}$ fertilities are not correlated at all. This suggests that the sterility in $F_{1}$ and that in $F_{2}$ stand on different genetic bases.

Variations in fertility of $F_{2}$ plants were then investigated with a number of crosses which had shown a high fertility in $F_{1}$. The results proved, as given in Table 1 , that the $F_{2}$ plants varied within a range of fertilities, with different modes according to the cross.

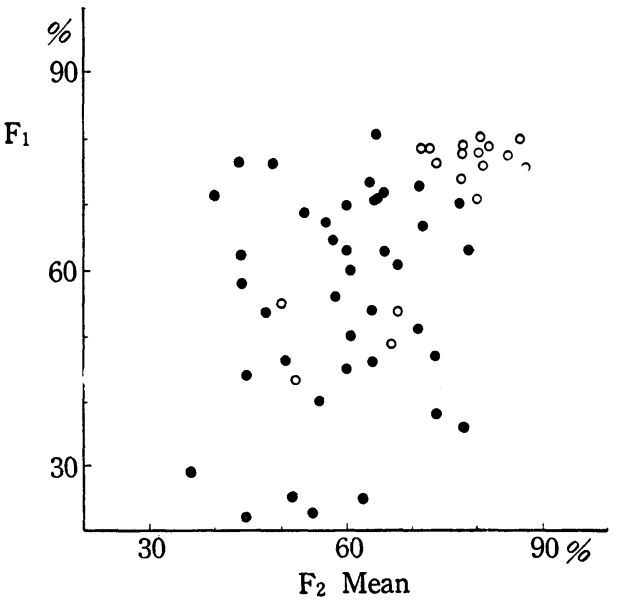

Fig. 1. Comparison between fertility of $\mathrm{F}_{1}$ hybrid and mean fertility of $\mathrm{F}_{2}$ population.

Several of those partially sterile $\mathrm{F}_{2}$ plants were then selected, and the progeny lines were raised. In general, they grew normally without a tendency of vegetative characters to deterioration, and showed both seed and pollen sterilities in parallel. For maintaining those lines, a plant showing a medium degree of sterility in each line was self-pollinated to produce the progeny line. Variations in seed fertility of $\mathrm{F}_{3}$ to $F_{6}$ lines thus obtained from two crosses, $1 \times 719$ and $563 \times 104$, are given in Table 2 . The data in the table would suggest that some $F_{3}$ lines might be segregating but others might be more homozygous for sterility; the $\mathrm{F}_{4}$ and later generation lines, though they consistently showed a range of fertility, tended to be more convergent than in $F_{3}$ and had a mode characteristic of the line.

Seed fertility is a character relatively easily affected by environment; in segregating populations, further, many genes may work as modifiers. It may then be assumed that the lines showing a certain range of reduced fertilities, obtained from 
Table 1. Examples showing occurrence of partially sterile $F_{2}$ plants from fertile $F_{1}$ hybrids

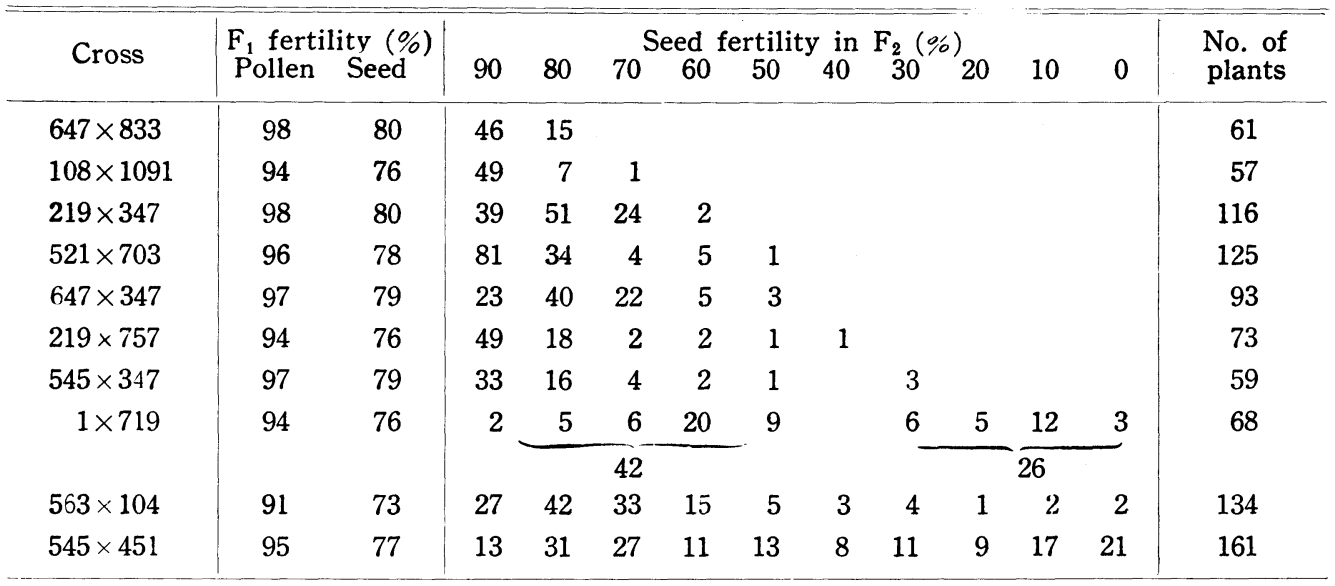

(Data taken in Taichung)

Table 2. Variation in seed fertility of $F_{3}$ to $F_{6}$ lines derived from partially sterile $F_{2}$ plants

\begin{tabular}{|c|c|c|c|c|c|c|c|c|c|c|c|c|}
\hline $\begin{array}{l}\text { Cross and } \\
\text { line no. }\end{array}$ & $\begin{array}{l}\text { Fertility } \\
\text { of parental } \\
\text { plant }(\%)\end{array}$ & 90 & 80 & $\begin{array}{l}\text { Dis } \\
70\end{array}$ & $\begin{array}{l}\text { ribu } \\
60\end{array}$ & ion of & $\begin{array}{l}\text { fer } \\
40\end{array}$ & $\begin{array}{c}\text { ility } \\
30\end{array}$ & $\begin{array}{r}(\%) \\
20\end{array}$ & 10 & 0 & $\begin{array}{l}\text { No. of } \\
\text { plants }\end{array}$ \\
\hline \multicolumn{13}{|c|}{$1 \times 719$ (in Taichung) } \\
\hline$F_{3}-25$ & 32 & & 1 & 1 & 1 & 3 & 6 & 3 & 1 & & 1 & 17 \\
\hline-32 & 52 & & & 4 & 8 & 2 & 2 & 1 & & & & 17 \\
\hline-33 & 51 & 2 & 2 & 4 & 5 & 3 & 2 & 2 & & & & 20 \\
\hline $\mathrm{F}_{4}-25-1^{*}$ & 40 & & 2 & 7 & 11 & 13 & 13 & 12 & 5 & 4 & & 67 \\
\hline \multicolumn{13}{|c|}{$563 \times 104$ (in Misima) } \\
\hline$F_{3}-37$ & 36 & & 2 & 2 & 1 & & 1 & 2 & & & & 8 \\
\hline-46 & 28 & & & & & & & 2 & 1 & 4 & 3 & 10 \\
\hline-55 & 39 & & & & & 1 & 3 & 12 & 4 & & & 20 \\
\hline-107 & 14 & & & 1 & 1 & 3 & 2 & 2 & 1 & & & 10 \\
\hline$F_{4}-37-2$ & 30 & & & & & & 2 & & 3 & 11 & 4 & 20 \\
\hline$-107-2$ & 37 & & & & & & 3 & 8 & 2 & 2 & 4 & 19 \\
\hline$F_{5}-37-2-1$ & 5 & & & & & & 3 & 4 & 15 & 10 & & 32 \\
\hline$-37-2-3$ & $37)^{*} 8$ & & & & 1 & 1 & 2 & 4 & 14 & 17 & & 39 \\
\hline$-37-2-4$ & 10 & & & 1 & & 2 & 3 & 4 & 12 & 16 & & 38 \\
\hline$-37-2-5$ & 10 & & & & 1 & & 2 & 8 & 19 & 10 & & 40 \\
\hline$-107-2-1$ & 27 & & & & & & & 1 & 10 & 29 & & 40 \\
\hline \multicolumn{2}{|c|}{$-107-2-2(\mathrm{~S} 107) * 28$} & & & 1 & 1 & 2 & 6 & 13 & 13 & 4 & & 40 \\
\hline $\mathrm{F}_{8} \quad \mathrm{~S} 37$ & 8 & & 2 & 3 & 4 & 4 & 16 & 29 & 79 & 54 & & 191 \\
\hline $\mathrm{S} 107$ & 27 & & & 2 & 2 & 5 & 10 & 21 & 23 & 17 & & 80 \\
\hline
\end{tabular}

* Lines whose parental plant was used for back-crossing. 
this breeding experiment, are homozygous for a certain combination of genetic factors which exert some unfavorable effect on the development of gametes. In view of the capability of breeding true, the partial sterility cannot be due to segregation of gametes having special genotypes.

It may be expected that the sterility under observation would be more dependent upon environment than that of $\mathrm{F}_{\mathrm{i}}$ hybrids which is determined by gametic segregation. This expectation was evidenced as follows: The variance of seed fertility (in percent) between panicles of the same plants in partially sterile $F_{4}$ lines was on the average 107.3, while that in partially sterile $F_{1}$ hybrids was as small as 23.0 and that in X-ray induced translocation heterozygotes was 41.0. Such a large environmental variance in the partially sterile lines may account at least partly for the wide range of their variation in fertility. It was also found that pollen fertility in thcse lines fluctuated in wider range than seed fertility, in contrast to the contrary situation in $F_{1}$.

\section{Genetic experiments for the sterility of hybrid progeny}

A. First experiment: A partially sterile line derived from $1 \times 719$ : The parental strains, 1 and 719, represent cultivated varieties obtained from Vietnam and South China, respectively. They both belong to the Indica or Continental type and their $F_{1}$ hybrid was completely pollen- and seed-fertile. However, partially sterile plants were found in $F_{2}$ (Table 1), and their derivative $F_{3}$ lines showed a range of reduced fertility (Table 2). An $\mathrm{F}_{3}$ plant with about $40 \%$ fertility was back-crossed with the parental strains, and fertility variations in the first and second generations of the back-crosses were observed. The same plant was also self-pollinated. The results are given in Table 3.

Table 3. Variation in fertility of two rice strains, 1 and 719 , a partially sterile line derived from their hybrid and its back-cross progeny

\begin{tabular}{|c|c|c|c|c|c|c|c|c|c|c|c|}
\hline Line & 90 & 80 & $\begin{array}{l}\text { Distr } \\
70\end{array}$ & $\begin{array}{l}\text { ibution } \\
60\end{array}$ & $\begin{array}{l}n \text { of } \mathrm{s} \\
50\end{array}$ & 40 & $\begin{array}{c}\text { tility } \\
30\end{array}$ & $\begin{array}{r}(\%) \\
20\end{array}$ & 10 & 0 & No. of plants \\
\hline 1 & 9 & 31 & 11 & & & & & & & & 51 \\
\hline 719 & 2 & 4 & 3 & 1 & & & & & & & 10 \\
\hline$F_{4}(25-1)$ & & 2 & 7 & 11 & 13 & 13 & 12 & 5 & 4 & & 67 \\
\hline $\begin{array}{c}(25-1) \times 1 \\
F_{1}\end{array}$ & & & 1 & 1 & 2 & 1 & & & & & 5 \\
\hline $\mathrm{F}_{2}$ & & 5 & 5 & 9 & 11 & 6 & 1 & & 1 & 1 & 39 \\
\hline (Exp.) & & 9.2 & 7.0 & 5.7 & 6.0 & 5.3 & 3.4 & 1.6 & 0.6 & 0.1 & $\chi^{2}=9.94 \quad \mathrm{P}>0.05$ \\
\hline $\begin{array}{c}(25-1) \times 719 \\
F_{1}\end{array}$ & & & & 1 & 2 & 1 & 1 & & & & 5 \\
\hline $\mathrm{F}_{2}$ & 5 & 20 & 9 & 17 & 16 & 14 & 16 & 8 & 3 & 1 & $10 s$ \\
\hline (Exp.) & 4.2 & 17.4 & 14.6 & 14.7 & 15.3 & 17.7 & 13.6 & 7.3 & 2.9 & 1.3 & $\chi^{2}=4.28 \mathrm{P}>0.50$ \\
\hline
\end{tabular}


As Table 3 shows, the $F_{1}$ of the back-crosses were partly sterile, and in $F_{2}$, though the fertility varied continuously, the frequency of fertile plants could be judged to be about one fourth. In view of the similar mode of variation to that in $F_{3}$ being found in the $\mathrm{F}_{4}$ progeny (Table 2), the $\mathrm{F}_{3}$ plant used for back-crosses could be regarded as homozygous for a sterility factor. The segregation ratio in back-cross $\mathrm{F}_{2} \mathrm{~S}$ was then presumed to be $1: 2: 1$, and a theoretical distribution of fertility was computed under the assumption that the variation due to other causes than the supposed factors follows a normal distribution with the same mean and standard deviation as those of the fertile parental strains in fertile plants, and those of the partially sterile line in partially sterile plants. Though this is quite a rough estimation, the observed distributions gave good fits to the expected ones thus computed, as shown in Table 3. A tentative conclusion was then drawn that the partially sterile line might differ from both parental strains in one major factor controlling fertility.

B. Second experiment: Partially sterile lines derived from $563 \times 104$ : In the first experiment, an $F_{3}$ plant which was not surely homozygous was used for crosses, and the number of plants observed was not sufficiently large. In order to cover this defect, another series of experiments was conducted. The maternal strain used, 563, was of Japanese origin and belonged to the Japonica or Temperate-Insular type; the pollen parent, 104, was a native variety of Taiwan belonging to the Indica or Continental type. Both were insensitive to photoperiod. Though the $F_{1}$ hybrid showed a high fertility, a number of partially sterile plants occurred in $F_{2}$ (Table 1), and partially sterile lines were derived from them (Table 2). Two such lines, S37 and S107 were used for the crossing experiment. They may be regarded as true-breeding for sterility, since the same mode of variation in fertility was found from $F_{4}$ through $F_{6}$. Two $\mathrm{F}_{4}$ plants taken from one and the other of the two lines were back-crossed to the parental strains respectively (i.e. S $37 \times 563, \mathrm{~S} 37 \times 104, \mathrm{~S} 107 \times 563$ and $\mathrm{S} 107 \times 104$ ), and the $F_{1}, F_{2}$ and $F_{3}$ lines of the thus resulting four crosses were investigated. The $\mathrm{F}_{2}$ plants were raised first in 1958, but were grown again in 1959 together with $\mathrm{F}_{3}$ lines for taking records simultaneously.

The fertility variations observed are given in Table 4. As shown in the table, the distributions were continuous and determination of a segregation ratio seemed to be difficult. Biometrical analysis was then attempted: The class-values given in percent were transformed into arc-sines, and the genetic components of variances were estimated by Mather's method (Mather 1949). The difficulty with this computation was that the partially sterile lines had apparently larger environmental variance than the fertile parental strains. Conventionally, the average of the large and small variances was used as $E_{1}$, and $E_{2}$ was derived from it as $E_{1} / n$. In spite of this and other difficulties, as shown in Table 5 , the observed variances generally showed good fits to the expected ones in all the four crosses, and the fixable and non-fixable genetic components. $D$ and $H$, could be estimated rather successfully. The number of effective factors, $K_{1}=\left(\bar{P}_{1}-\bar{P}_{2}\right)^{2} / 4 D$, thus estimated, ranged from 1.59 to 2.08 among the four crosses. 
Table 4. Seed fertility distributions in parental strains 563 and 104, partially sterile lines S37 and S107, and their hybrids

\begin{tabular}{|c|c|c|c|c|c|c|c|c|c|c|c|}
\hline Population & $\begin{array}{l}\text { Fertility } \\
\text { of parental } \\
\text { plant }(\%)\end{array}$ & 90 & 80 & $\begin{array}{l}\text { Dist } \\
70\end{array}$ & $\begin{array}{l}\text { ibution } \\
60\end{array}$ & $\begin{array}{l}\text { of } f \\
50\end{array}$ & $\begin{array}{l}\text { fertility } \\
\quad 40\end{array}$ & $\begin{array}{l}(\%) \\
30\end{array}$ & 20 & 10 & $\begin{array}{l}\text { No. of } \\
\text { plants }\end{array}$ \\
\hline 563 & & 9 & 12 & 2 & 1 & 1 & & & & & 25 \\
\hline 104 & & 16 & 10 & 1 & & & & & & & 27 \\
\hline S37 $\left(\mathrm{F}_{6}\right)$ & 7.6 & & 2 & 3 & 4 & 4 & 16 & 29 & 79 & 54 & 191 \\
\hline $\mathrm{F}_{2}: \mathrm{S} 37 \times 563$ & $20.6^{*}$ & 2 & 9 & 10 & 9 & 17 & 11 & 16 & 12 & 8 & 94 \\
\hline $\mathrm{S} 37 \times 104$ & $56.5^{*}$ & 1 & 4 & 15 & 12 & 10 & 7 & 12 & 5 & 8 & 74 \\
\hline \multicolumn{12}{|l|}{ 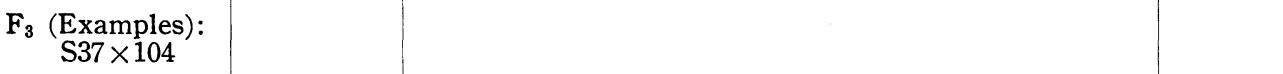 } \\
\hline$-1(A A)$ & 79.0 & 3 & 9 & 12 & 9 & 4 & 2 & & & & 39 \\
\hline$-2(A a)$ & 50.0 & & 2 & 5 & 5 & 5 & 4 & 9 & 4 & 5 & 39 \\
\hline$-3(a a)$ & 34.0 & & & 1 & & 2 & 2 & 3 & 11 & 19 & 38 \\
\hline $\mathrm{S} 107\left(\mathrm{~F}_{6}\right)$ & 26.5 & & & 2 & 2 & 5 & 10 & 21 & 23 & 17 & 80 \\
\hline $\mathrm{F}_{2}: \mathrm{S} 107 \times 563$ & $56.1 *$ & 3 & 17 & 20 & 12 & 17 & 25 & 24 & 24 & 18 & 160 \\
\hline $\mathrm{S} 107 \times 104$ & $52.7^{*}$ & & 5 & 9 & 13 & 10 & 7 & 14 & 14 & 7 & 79 \\
\hline \multicolumn{12}{|l|}{$\mathrm{F}_{3} \underset{\mathrm{S} 107 \times 104}{(\text { Examples }):}$} \\
\hline$-1(A A)$ & 77.0 & 9 & 10 & 11 & 5 & 4 & 1 & & & & 40 \\
\hline$-2(A a)$ & 22.0 & & 2 & 6 & 5 & 4 & 2 & 2 & 7 & 11 & 39 \\
\hline$-3(a a)$ & 8.0 & & 1 & 2 & 2 & 4 & 5 & 9 & 5 & 12 & 40 \\
\hline
\end{tabular}

(In Misima, 1959)

It may be taken for granted that many genes can influence fertility as modifiers. The estimated numbers of effective factors given above would indicate that one major factor $A$ and several modifiers are concerned. Under this assumption, the additive effect of the major factor was estimated as $d_{u}=2 D / \bar{P}_{1}-\bar{P}_{2}$. This implies that $\bar{d}=$ $S d_{i}{ }^{2} / S d_{i}$, that is a condition not realized unless all relevant genes have equal effects. However, substituting numerical examples into the formulas, the bias was found to be relatively small when one major and a few minor factors were concerned. The values determined by the genotypes $A A$ and $a a$ were then assumed to be $d_{a}$ and $-d_{a}$ (from the mid-parental value), respectively. The dominance effect of the factor, or the value of the heterozygote $A a$, was estimated as $h_{a}=2 \times\left(\bar{F}_{2}-\right.$ mid-parental value), assuming that the modifiers have dominance effects in both plus and minus directions. It was assumed further that the residual $\mathrm{F}_{2}$ variance, $\mathrm{V}_{F_{2}}-1 / 2 d_{a^{2}}-1 / 4 h_{a}{ }^{2}$, which comprises the genetic variance due to modifiers and the environmental variance, is represented by a normal distribution. On the basis of these estimations, a theoretical $\mathrm{F}_{2}$ distribution of fertility was computed for each cross, and was compared with the observed distribution. The results are given in the lower part of Table 5, together with the estimates of $d_{a}$ and $h_{a}$. The chi-square values for the deviations of observed from expected distributions were not large enough to indicate a discrepancy.

C. Consideration on sterility factors: The above-mentioned experiment showed, in the same manner as in the first one, that the partially sterile lines might differ 
Table 5. Means and variances of fertility in $\operatorname{arc}$-sin $\sqrt{\text { percentage, }}$ genetic components of variance estimated $\left(D\right.$ and $H$ ), number of segregating factors $\left(\mathrm{K}_{1}\right)$, effects of a presumed factor $\left(d_{a}\right.$ and $\left.h_{a}\right)$, and chi-square values between observed and expected fertility distributions

\begin{tabular}{|c|c|c|c|c|}
\hline Item & S $37 \times 563$ & $\mathrm{~S} 37 \times 104$ & $\mathrm{~S} 107 \times 563$ & $\mathrm{~S} 107 \times 104$ \\
\hline Mean, & \multirow[b]{2}{*}{27.61} & \multirow[b]{2}{*}{27.61} & \multirow[b]{2}{*}{30.68} & \multirow[b]{2}{*}{30.68} \\
\hline$\overline{\mathrm{P}}_{1}$ & & & & \\
\hline$\overline{\mathrm{P}}_{2}$ & 64.58 & 68.02 & 64.58 & 68.02 \\
\hline$\overline{\mathrm{F}}_{2}$ & 41.84 & 43.11 & 40.92 & 40.24 \\
\hline Variance, & (Obs.) (Exp.) & (Obs.) (Exp.) & (Obs.) (Exp.) & (Obs.) (Exp.) \\
\hline $\mathrm{V}_{F 2}$ & $172.9 \quad 176.6$ & $185.6 \quad 191.1$ & $206.5 \quad 213.6$ & $\begin{array}{ll}172.7 & 186.8\end{array}$ \\
\hline $\mathrm{V}_{F 3}$ & $83.1 \quad 91.8$ & $90.7 \quad 102.6$ & $95.4 \quad 105.9$ & 87.0 \\
\hline $\mathrm{W}_{F 2 / F 3}$ & 107.7 & 122.4 & 131.3 & 114.8 \\
\hline$\overline{\mathrm{V}}_{F_{3}}$ & $112.7 \quad 114.0$ & 120.6 & 135.5 & 139.1 \\
\hline$E_{1}$ & 51.4 & 50.0 & 50.1 & 56.8 \\
\hline $\mathrm{E}_{2}$ & $1.4 \quad-7.2$ & $1.4-10.5$ & -9.2 & -9.4 \\
\hline$D$ & $180.5 \pm 43.4$ & $207.4 \pm 59.4$ & $197.9 \pm 53.6$ & $199.3 \pm 72.6$ \\
\hline$H$ & $139.5 \pm 138.8$ & $149.6 \pm 190.2$ & $258.3 \pm 171.6$ & $121.5 \pm 232.2$ \\
\hline $\mathrm{K}_{1}$ & $2.08 \pm \quad 0.40$ & $1.81 \pm \quad 0.41$ & $1.60 \pm \quad 0.34$ & $1.59 \pm \quad 0.42$ \\
\hline$d_{a}$ & 9.32 & 10.71 & 11.12 & 11.20 \\
\hline$h_{a}$ & -10.30 & -7.75 & -15.20 & -16.56 \\
\hline$\chi^{2}(\mathrm{df}=8)$ & 6.79 & 17.72 & 14.23 & 12.84 \\
\hline $\mathbf{P}$ & $>0.50$ & $\fallingdotseq 0.05$ & $>0.05$ & $>0.10$ \\
\hline
\end{tabular}

from their parental strains in one major factor. The fact that those lines were derived from a hybrid between normally fertile strains indicates the duplicated nature of the sterility factor. Accordingly the following assumption could be made: The parental strains have the genotypes $A_{1} A_{1} a_{2} a_{2}$ and $a_{1} a_{1} A_{2} A_{2}$ respectively, and the true-breeding partially sterile lines are $a_{1} a_{1} a_{2} a_{2}$. Since the $F_{1}$ between parental strains $\left(A_{1} a_{1} A_{\Sigma} a_{2}\right)$ was fertile and the first back-crosses $\left(A_{1} a_{1} a_{2} a_{2}\right.$ or $\left.a_{1} a_{1} A_{2} a_{2}\right)$ were partially sterile, and the estimated values of $h_{a}$ were as large as those of $d_{a}$ and minus in sign, at least two dominant $A$ 's $\left(A_{1} A_{1}, A_{2} A_{2}\right.$ or $\left.A_{1} A_{2}\right)$ might be needed for normal fertility. Thus, the partially sterile lines, when crossed with the parental strain, segregate into 1 fertile and 3 partially sterile plants in $\mathrm{F}_{2}$. If plants with one dominant $A$ has a higher fertility than those with none, the $F_{2}$ ratio would be $1: 2: 1$ as suggested in the first experiment. It is then expected that the $F_{2}$ between parental strains would segregate into 11 fertile and 5 sterile plants. This segregation was assumed in the cross $1 \times 719$ (first experiment); as shown in Table 1, a 42:26 ratio, consistent with 46.7:21.3 or $11: 5$, was found if the range of fertility was divided into fertile and sterile classes in accordance with a discontinuity in frequency distribution.

The above-assumption of duplicate factors is a working hypothesis. As Muller (1940) has postulated, another explanation for the sterility in question would be 
disharmonic interaction of two complementary gene systems. With the actual data, however, this assumption failed to fit better, and the duplicate factor hypothesis appeared to allow for the simplest explanation of the data. The sterility factors postulated above will be called Duplicate-fertility genes, assuming that they may be said to be genes as will be discussed later.

D. Linkage between sterility and apiculus coloration: A linkage relation was found between one of the fertility genes and the gene for apiculus coloration, $C$, as follows: The partially sterile line S37 had a purple coloration at the apiculus. The parental strain 563 was also colored at the apiculus, while strain 104 was colorless, and their genotypes for this character were determined to be $C S p$ and $c S p$ respectively. Accordingly, S37 should have CSp. It was found that in the $\mathrm{F}_{2} \mathrm{~S} 37 \times 104$, the colored class had more sterile plants than the colorless one, as shown in Table 6 . Since as to fertility genes S37 and 104 would be of the genotypes $a_{1} a_{1} a_{2} a_{2}$ and $A_{1} A_{1} a_{2} a_{2}$,

Table 6. Linkage between fertility and apiculus coloration found in the $F_{2} S 37 \times 104$

\begin{tabular}{|c|c|c|c|c|c|c|c|c|c|c|c|c|}
\hline Apiculus & 90 & 80 & $\begin{array}{c}\text { Dist } \\
70\end{array}$ & $\begin{array}{c}\text { ribut } \\
60\end{array}$ & $\begin{array}{c}\text { on of } \\
50\end{array}$ & $\begin{array}{c}\text { fert } \\
40\end{array}$ & $\begin{array}{l}\text { lity } \\
30\end{array}$ & in $\%$ & 10 & 0 & $\begin{array}{l}\text { No. of } \\
\text { plants }\end{array}$ & $\begin{array}{c}\text { Mean } \\
\text { fertility } \\
\left(\sin ^{-1} \sqrt{ } \%\right)\end{array}$ \\
\hline Purple & 1 & 2 & 7 & 8 & 8 & 5 & 15 & 6 & 6 & 3 & 61 & 38.1 \\
\hline Colorless & 5 & 8 & 6 & 7 & 1 & 2 & & 3 & 2 & & 34 & 53.0 \\
\hline
\end{tabular}

(In Misima, 1958)

respectively, the $\mathrm{F}_{1}$ is expected to have the combination of genes $A_{1}-c / a_{1}-C$. Letting the recombination fraction be $p$, we have the following expressions for the mean fertilities of colored and colorless classes.

Colored: $\quad(1-2 p) d_{a}+2\left(p-p^{2}\right) h_{a}$

Colorless: $\quad \frac{1}{3}\left[-(1-2 p) d_{a}+2\left(1-p+p^{2}\right) h_{a}\right]$

Then the difference in fertility between the two classes must be

$$
\frac{4}{3}(1-2 p) d_{a}-\frac{2}{3}(1-2 p)^{2} h_{a},
$$

while the actual difference was 14.9 (in arc-sine transformation), and the values of $d_{a}$ and $h_{a}$ were 10.71 and -7.75 as shown in Table 5 . The recombination fraction $p$ was estimated from these values to be 0.095 or $9.5 \%$.

On the other hand, the partially sterile line S107 had colorless apiculus. In its cross with 563, the apiculus coloration and fertility showed no linkage relation. This suggests that if S107 and S37 had the same fertility genes $a_{1} a_{1} a_{2} a_{2}$, the second pair $A_{2} A_{2}$ carried by 563 would not be linked with $C$.

3. Embryological observation of partially sterile plants

Since a similar range of sterility was seen in both seed set and production of pollen grains, an investigation of the process of gametogenesis was carried out by the junior writer. Spikelets at different developmental stages were fixed in acetic alcohol, paraffin-sectioned and were stained with Heidenhein's haematoxylin.

The main results obtained were as follows: No disturbances in the pairing and 
disjunction of chromosomes were found in more than 100 PMC's observed, and tetrads of micro- and mega-spores were formed normally. The nucellar as well as the tapetal tissues showed no irregularity. In the ovules, in about a half of 99 cases observed, all four cells resulting from meinsis appeared as a degenerated strongly stainable mass before the first embryosac mitosis (Fig. 2a). At the stage of anthesis, those ovules had still trace of it (Fig. 2b). In anthers, the first symptom of degeneration appeared at the stage of first pollen mitosis, but it became clearly recognizable a few days before anthesis when a part of pollen grains failed to produce starch (Fig. 2c).

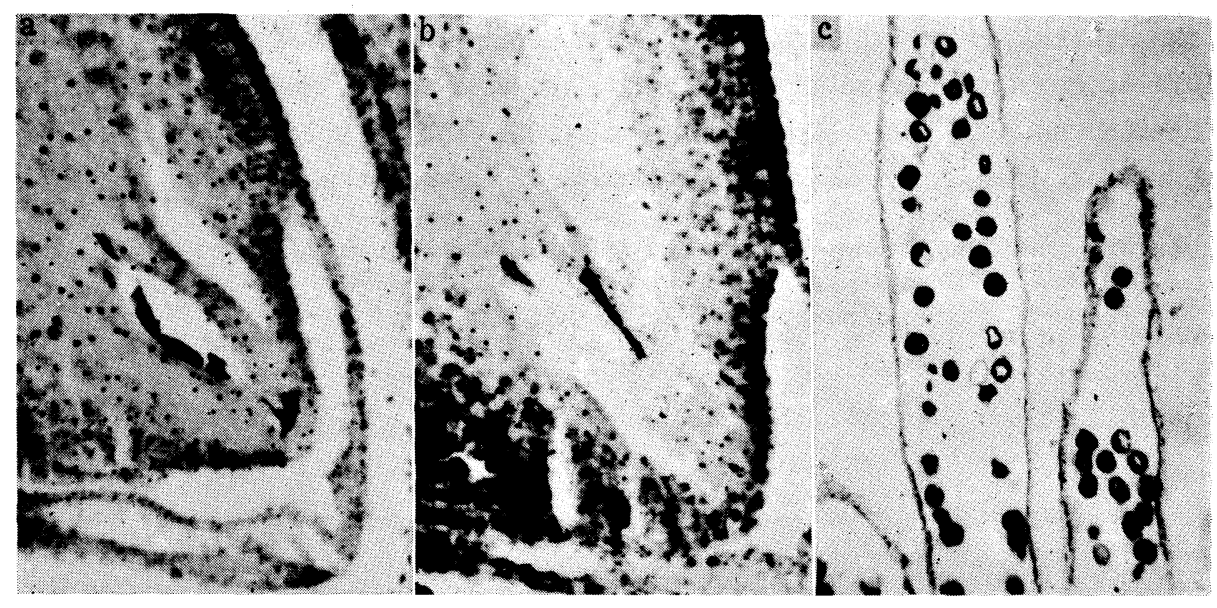

Fig. 2. Photomicrographs showing degeneration of gametes in a partially sterile line, S37. $(\times 125)$

a) An ovule a few days after meiosis. b) An ovule a little before anthesis.

c) Anthers a little before anthesis.

A similar observation was formerly made by the senior writer regarding the sterility of $F_{1}$ hybrids. In that case, the first symptom of degeneration in the ovules was a delay of the first embryosac mitosis, and the frequency of ovules with such a delay or degenerating embryosacs increased with the stage (the stage was estimated by the size of ovule). Also in anthers, the degeneration of microspores was found to begin at the stage of first mitosis, which was characterized by a slowing down of growth in diameter relative to the anther length.

It may then be suggested than in both the sterile $F_{1}$ hybrids and the progeny lines, the degeneration of gametes similarly appears as the break.down of haploid mitosis, though in the former case the gametic genotype, and in the latter the plant genotype, might be responsible for the degeneration. It may be inferred that haploid mitosis is a critical process easily upset by genetic disharmonies.

\section{Discussion}

Referring to many cases in plants and animals, Stebbins (1958) has classified the isolation mechanisms between species which can be hybridized into weakness or 
inviability, sterility and breakdown of hybrids. Considering the genetic basis of these phenomena, he has divided further the sterility of hybrids, which includes various types of failure of reproductive processes, into haplontic and diplontic sterilities; the former represents deterioration of gametes carrying numerically irregular chromosomecomplements or certain rearrangements of chromosomes or genes, which result either from non-disjunction or from recombination in meiosis. The latter represents an upset of gametogenesis due to a certain diploid genotype of hybrid individuals.

In cultivated rice (Oryza sativa), the partial sterility of intervarietal $F_{1}$ hybrids is apparently haplontic, as formerly demonstrated by the senior writer (Oka 1953, 1957b). In contrast, the partial sterility dealt with in this study seems to be diplontic, since it could be bred true. No particular abortion of reproductive organs was found other than the deterioration of male and female gametes at a certain developmental stage; it seems that the causal genetic factors obstruct some physiological process in the reproductive organs, for instance, nutrient supply. In view of its occurrence in $\mathrm{F}_{2}$ and later generations, however, this sterility should be regarded as belonging to the category of hybrid breakdown. An important difference between what is usually known as $F_{1}$ sterility and the present phenomenon is that the former is limited to heterozygotes and causes gametic selection, while the latter occurs in homozygotes and results in zygotic elimination.

The senior writer formerly reported another case of hybrid breakdown in rice, in which an upset of vegetative growth was caused by a set of complementary recessive lethals (Oka 1957a). In that case, the parental normal strains were postulated to have the genotypes $A_{1} A_{1} a_{2} a_{2}$ and $a_{1} a_{1} A_{2} A_{2}$. The $\mathrm{F}_{1}, A_{1} a_{1} A_{2} a_{2}$ was then normal, while the $\mathrm{F}_{2}$ segregated into 11 normal and 5 weak plants, and the back-crosses $\left(\mathrm{F}_{1} \times\right.$ parents) showed a 3 normal to 1 weak ratio. It was accordingly assumed that at least two $A$ 's would be necessary for normal growth. This genic system is just the same as that postulated in the present study for partial sterility; their common feature is that the factors are duplicated and can compensate for each other but at least two dominants are needed for normal development. A tendency toward breakdown is frequently met with in the progeny of hybrids between distantly related rice variaties, though the weak or sterile plants may be rapidly eliminated from hybrid populations. It seems that such duplicate factors as described above are widely spread in rice varieties.

Thus, the isolating barriers (or the outcome of differentiation) so far found in hybrids between cultivated rice varieties are, in the order of alternation of generations, listed as follows:

\begin{tabular}{|c|c|c|c|}
\hline Phenomenon & Genetic basis & Coincidence & Reference \\
\hline Weakness of $F_{1}$ plants & Complementary dominant lethals & Rare & Oka 1957a \\
\hline $\begin{array}{l}\text { Partial sterility of } F_{1} \\
\text { plants }\end{array}$ & $\begin{array}{l}\text { "Gametic-development genes" } \\
\text { (Complementary haplontic lethals) }\end{array}$ & Common & $\begin{array}{l}\text { Oka } 1954 \text { and } \\
\text { many others }\end{array}$ \\
\hline $\begin{array}{l}\text { Hybrid breakdown, } \\
\text { a) Weakness }\end{array}$ & Complementary recessive lethals & Common (?) & Oka 1957 a \\
\hline b) Partial sterility & "Duplicate-fertility genes" & Common & Present study \\
\hline
\end{tabular}


All these phenomena listed above could be explained on the basis of duplicate or complementary factors, but the two kinds cannot be strictly distinguished; duplicate genes whose recessive combinations have a deteriorating effect may be said to be complementary lethals either haplontic or diplontic. It seems that duplication of genes can be a basic feature of rice germplasm, if differences between distantly related strains are considered. As the senior writer has formerly suggested (Oka 1957a), an explanation for the origin of this situation might be that in remote ancestry the chromosomes had been doubled with following deficiencies of small segments or recessive genic mutations at different loci occurring in different populations. As also discussed by him, this situation might have enabled the species to enjoy a large potentiality of genetic variation.

Regarding the sterility of $\mathrm{F}_{1}$ hybrids, many workers have assumed the presence of cryptic structural differences between the parental chromosomes, though the cytological evidence has always been inconclusive (Sampath and Mohanty 1954; Yao et al. 1958; Henderson et al. 1959). Mr. S. Sampath of the Central Rice Research Institute, India, kindly told the writers that a deficiency-duplication hypothesis might be adopted for the sterility of true-breeding semi-sterile lines which he had obtained from an intervarietal cross, since he found in pollen mother cells of those plants quadrivalent chromosomes with a low frequency. It seems to the writers, however, that it would be idle to discuss whether the nature of the phenomenon is chromosomal or genic, because the problem involves the fine structure of genetic substance and no good method to solve it is yet available in the plant species under discussion. As Stebbins (1958, p. 178) has pointed out, "small chromosomal rearrangements could be expected to segregate in the same way as genes and to show similar linkage relationships." More important is the genetic behavior of the phenomena, since it may contribute to the solution of problems in the field of breeding and evolution. Since they behave as genes, the duplicate factors postulated in the present study may be called "Duplicatefertility genes."

\section{Summary}

The gametic-development gene hypothesis, formerly put forward by the senior writer, could convincingly explain the sterility of $F_{1}$ hybrids and related phenomena in cultivated rice, but could not account for the occurrence of sterility in $F_{2}$ and later hybrid derivatives. It was found that among many intervarietal crosses, $F_{1}$ fertility and mean $\mathrm{F}_{2}$ fertility were not correlated. Experiments were then conducted to throw a light on the genetic basis of sterility of the latter type, using cross combinations which showed a high fertility of $F_{1}$ hybrids. Their fertility in $F_{2}$ segregated in a wide range, and from a few partially sterile $F_{2}$ plants, partially sterile lines which bred true for sterility have been established. Embryological observations showed that both male and female gametes partly degenerate after normal meiosis.

The partially sterile lines were then back-crossed to the parental strains, and the 
$F_{1}, F_{2}$ and $F_{3}$ generations were investigated regarding fertility variation. The results led to the conclusion that duplicate factors might be involved sustaining the development of gametes on the condition that at least two dominants are present in the plant, and that this diplontic sterility might be due to certain recessive combinations of those factors. The parental strains were considered to have different combinations, $A_{1} A_{1} a_{2} a_{2}$ and $a_{1} a_{1} A_{2} A_{2}$. A linkage relation was found between such a fertility factor and the apiculus pigmentation gene $C$. In the sense that those factors behave as genes, they were called Duplicate-fertility genes. The genetic basis of this sterility thus postulated is similar to that formerly shown for the segregation of weak plants in $F_{2}$. Both phenomena, which spell a breakdown of hybrids, seems to be the isolating barriers frequently found in rice.

\section{Literature cited}

Henderson, M. T., B. P. Yeh and B. Exner 1959 Further evidence of structural differentiation in the chromosomes as a cause of sterility in intervarietal hybrids of rice, Oryza sativa L. Cytologia 24: 415-422.

Mather, K. 1949 Biometrical genetics. Methuen \& Co., London.

Muller, H. J. 1940 “The new systematics" (Edited by J. Huxley), Oxford Univ. Press, London and New York: 185-268.

Oka, H. I. 1953 The mechanism of sterility in intervarietal hybrids. (Phylogenetic differentiation of cultivated rice, 6) Jap. Jour. Breed. 2: 217-224. (Jap. with Eng. résumé) 1954 Classification of rice varieties by intervarietal hybrid sterility. (Ditto, 2) Jap. Jour. Breed. 3: 1-6. (Jap. with Eng. résumé) 1957a Complementary lethal genes in rice. (Ditto, 15) Jap. Jour. Genet. 32: 83-87. $1957 \mathrm{~b}$ Genic analysis for the sterility of hybrids between distantly related varieties of cultivated rice. Jour. Genet. 55: 397-409.

Sampath, S. and H. K. Mohanty 1954 Cytology of semi.sterile rice hybrids. Current Sci. 23: $182-183$.

Stebbins, G. L. 1958 The inviability, weakness, and sterility of interspecific hybrids. Adv. in Genet. 9: 147-215.

Yao, S. Y., M. T. Henderson and N. E. Jodon 1958 Cryptic structural hybridity as a probable cause of sterility in intervarietal hybrids of cultivated rice, Oryza sativa L. Cytologia 23: $46-55$. 